\title{
IMPLEMENTING AND SUSTAINING MENTORING PROGRAMMES: A REVIEW OF THE APPLICATION OF BEST PRACTICES IN THE SOUTH AFRICAN ORGANISATIONAL CONTEXT
}

\author{
MARINA HATTINGH \\ MELINDE COETZEE \\ DRIES SCHREUDER \\ Department of Industrial and Organisational Psychology \\ College of Economic and Management Sciences \\ University of South Africa
}

\begin{abstract}
The objective of this study was to investigate best practices regarding implementing and sustaining formal mentoring programmes in three South African organisations. The purposeful sampling method was used to involve designated representatives responsible for overseeing the implementation and management of the mentoring programmes in each of the three companies in the research. A qualitative content analysis technique was applied to infer meaningful explanations to the research questions. The findings indicate that the three organisations rely on a variety of systems and practices to sustain the effectiveness of their mentoring programmes. The implications of the findings are discussed.
\end{abstract}

\section{OPSOMMING}

Die doel met hierdie studie was om die beste praktyke rakende die implementering en instandhouding van formele mentorskapprogramme in drie Suid-Afrikaanse organisasies te ondersoek. Doelmatigheidsteekproefneming is aangewend om aangewese verteenwoordigers wat verantwoordelik is vir die toesighouding en bestuur van die mentorskapprogramme in die drie maatskappye te betrek by die navorsing. 'n Kwalitatiewe inhoudsontledingstegniek is benut om betekenisvolle verklarings vir die navorsingvrae daar te stel. Die bevindinge dui daarop dat die drie organisasies van 'n verskeidenheid stelsels en praktyke gebruik maak om die doeltreffendheid van hulle mentorskapprogramme in stand te hou. Die implikasies van die bevindinge word bespreek.

The start of the $21^{\text {st }}$ century can best be described as challenging, changing, turbulent and unpredictable (Baruch, 2002; 2004; Gibb, 1995). It requires organisations to be more flexible and innovative, and demands that people develop a different set of skills. In this uncertain and changing world, mentoring provides an excellent option for people to develop themselves in order to keep ahead of the game (Baruch, 1999; 2002; Burke, McKeen \& McKenna, 1994; Finkelstein, Allen \& Rhoton, 2003; Gibb, 1995). Organisations in all industries have long recognised the growing importance of the role mentors can play in offering advice and direction, and in acting as a sounding board for employees (Bush \& Coleman, 1995; Cranwell-Ward, Bossons \& Gover, 2004; Clutterbuck, 2001; Clutterbuck \& Lane, 2005; Scandura \& Williams, 2002). In addition, organisations are increasingly realising how the relationship between mentor and mentee can benefit their business (Allen \& Poteet, 1999; Burke et al, 1994; Clutterbuck, 2001; Klasen \& Clutterbuck, 2002).

The traditional approach to mentoring targets specific groups within the organisation, such as graduate trainees, historically disadvantaged groups (Africans, Coloureds, Indians and women), new employees or fast-track management candidates (Blake-Beard, 2001; Clutterbuck, 2001; Gunn, 1995; Klasen \& Clutterbuck, 2002; Samier, 2000; Sketch, 2001). However, the range of applications and programmes that organisations are developing make it clear that mentoring can be more a state of mind than just a specific activity for the chosen few (Clutterbuck \& Lane, 2005; Cranwell-Ward et al, 2004). The more mentoring can be seen as central to an organisation's functionality rather than a minor activity, the more beneficial it will be in the long term (Gibb, 1995; Clutterbuck \& Lane, 2005; Cranwell-Ward et al, 2004; Klasen \& Clutterbuck, 2002). A successful mentoring relationship is one of the most motivating situations individuals can find themselves in as part of their

Requests for copies should be addressed to: M Coetzee, coetzm1@unisa.ac.za working life. If organisations can harness and tap into the energy that comes from this motivation, many performancelinked problems can disappear without any further direct involvement of the organisation or indirect use of scarce resources (Baruch, 2002; Clutterbuck, 2001; Clutterbuck \& Sweeney, 2003; Cranwell-Ward et al, 2004; Finkelstein et al, 2003; Hall \& Kahn, 2002).

\section{The context and rationale for mentoring}

Cranwell-Ward et al (2004) state that there are a number of external and internal factors that have influenced the rising importance of mentoring as a development tool. Tables 1 and 2 summarise these influences. It is evident that economic, organisational and individual elements interact to increase the importance of formal mentoring programmes in organisations (Baruch, 1999; 2002; Cranwell-Ward et al, 2004). Today's work environment demands that employees are ready and able to adapt to an ever-increasing pace of change. Managers are under continuous pressure to find new ways to obtain results and working methods that are costeffective and efficient, yet do not compromise quality (Baruch, 2002; Klasen \& Clutterbuck, 2002). To achieve this threefold outcome, many companies realise that substantial investment in employee development is vital. This investment, too, should be cost-effective and speedy, and it should produce high quality performance -- both now and in the long term. Under certain circumstances (for example, depending on the employee's development needs), mentoring can meet these criteria better than any other training and development method (such as coaching and conventional classroom-based training courses) (Baruch, 2002; 2004; Hall \& Kahn, 2002; Klasen \& Clutterbuck, 2002).

There is no doubt that one-on-one development approaches (such as coaching, networking/facilitation, counselling and guardianship) all have their place in the world of employee learning. However, a significant advantage mentoring has over any of these lies in its integrated approach. A second advantage 
is its capacity for creating individuals who are capable of, and motivated by, managing their own learning on a continuous basis. These two factors enable mentoring to achieve an impact and effectiveness that goes far beyond other one-to-one development approaches (Clutterbuck \& Lane, 2005; Clutterbuck \& Sweeney, 2003; Hall \& Kahn, 2002; Klasen \& Clutterbuck, 2002).

\section{Definition and benefits of mentoring}

Defining mentoring is rather complex, mainly because mentoring is as informal as pairing, as variable as the organisations in which mentors and mentees find themselves, and as distinctive as the people involved (Clutterbuck, 2001; Clutterbuck \& Lane, 2005; Corporate Leadership Council, 1999). The term "mentoring" is derived from Greek mythology and implies a relationship between a young adult and an older adult, where the more experienced adult helps the younger learn to navigate the adult world and the world of work (Kram, 1985). An informal, though more contemporary, definition (provided by Cranwell-Ward et al, 2004) describes mentors as people who help others to reach their potential. Triple Creek Associates (2004) provide a comprehensive definition of mentorship. They see mentoring as a personal enhancement strategy through which one person facilitates the development of another by sharing resources, expertise, values, skills, perspectives, attitudes and proficiencies. This strategy allows the learner to build skills and knowledge, and provides the experienced party with the opportunity to enhance his or her skills and knowledge.

Clutterbuck \& Lane (2005) emphasise the developmental nature of mentoring and therefore views mentoring as off-line help by one person to another in making significant transitions in knowledge, work or thinking. This description of mentoring is also the official definition of the European Mentoring Centre (Clutterbuck, 2001:3). The rationale behind this is as follows:

- Off-line is appropriate because it is difficult to be fully open in a relationship where one person has authority over the other.

- Help covers a wide range of resources for which the mentee can turn to the mentor (from direct advice to simply listening).
- One person to another. In developmental mentoring, the hierarchy is not important - it is the experience gap that matters. Peer mentoring is increasingly common; as is upward mentoring, where the mentor is more junior in terms of the hierarchy.

- Significant transition. Mentoring programmes and relationships require some sense of purpose if they are to achieve benefits for the participants.

Brown (1990) states that mentoring is an inclusive, confidential relationship between two people who have mutual personal growth and corporate success as common goals. Henley Management College (2000) concurs that mentoring is the creation of possibilities and the provision of guidance and support to others in a relationship of trust that includes facilitating growth, bringing visions to life and enabling people to achieve. Parsloe (1992) views the purpose of mentoring as that of helping and supporting people to manage their own learning in order to maximise their potential, develop their skills, improve their performance and become the persons they want to be.

Although the definitions of mentoring in the literature may vary, they do share general agreement with regard to the features of the mentoring relationship: mentoring is developmental in nature; mentoring is an evolving dynamic relationship between two individuals (namely the mentor and the mentee); mentoring is a partnership between two people, where the mentor works collaboratively with a mentee; mentoring can be mutually beneficial to both mentor and mentee, and also to the organisation; the relationship is one of equality in that the mentor and mentee each brings a different perspective to the process, and both parties are equally accountable for the success of the relationship. It should be noted that a mentoring relationship could start out as coaching, but slowly move towards guiding, directing and developing people rather than focusing on job-related improvement (Appelbaum, Ritchie \& Shapiro, 1994; Bush \& Coleman, 1995; Clutterbuck, 2001; Clutterbuck \& Lane, 2005; Clutterbuck \& Sweeney, 2003; Poe, 2002). This relationship offers a more holistic approach in that the mentees' achievements are seen in the context of their total development.

TABLE 1

CONTEXT AND RATIONALE FOR MENTORING: EXTERNAL INFLUENCES (CRANWELL-WARD ET AL, 2004)

\begin{tabular}{|c|c|c|}
\hline External influences & Description & Importance of mentoring \\
\hline Business environment & $\begin{array}{l}\text { An environment categorised by large-scale changes, achieving } \\
\text { more with less. }\end{array}$ & Emphasis switches to flexibility rather than specialisation. \\
\hline Globalisation & $\begin{array}{l}\text { Competing in a global marketplace, without boundaries such } \\
\text { as countries, cultures and technology. }\end{array}$ & $\begin{array}{l}\text { Requires that mentoring takes place electronically; mentoring } \\
\text { schemes focusing on a range of different cultures. }\end{array}$ \\
\hline Technological advancements & $\begin{array}{l}\text { Changes in the way organisations do business, in the way work } \\
\text { is conducted and the ways of learning. }\end{array}$ & Support people to take advantage of the available technology. \\
\hline Reorganisation of organisations & $\begin{array}{l}\text { Downsizing of organisations to become more competitive and } \\
\text { cost-effective. }\end{array}$ & $\begin{array}{l}\text { Help managers to cope with greater accountability for } \\
\text { performance, development of broader business perspective and } \\
\text { building the capacity to work across functional boundaries. }\end{array}$ \\
\hline Mergers and acquisitions & $\begin{array}{l}\text { Take over and integration of organisations in response to } \\
\text { increased competition. }\end{array}$ & $\begin{array}{l}\text { Working across merging companies to help integrate the culture } \\
\text { of merged organisation. }\end{array}$ \\
\hline Diversity management & $\begin{array}{l}\text { Changes in the demographics of the population, promotion } \\
\text { of equal opportunities, equality legislation and shortage of skills. }\end{array}$ & $\begin{array}{l}\text { Helps to empower mentees and supports the development of } \\
\text { leaders that appreciate the value of a culturally diverse } \\
\text { environment. }\end{array}$ \\
\hline Changing shape of development & $\begin{array}{l}\text { Management development initiatives are shorter, more directed } \\
\text { and more flexible. }\end{array}$ & $\begin{array}{l}\text { Support managers to gain a broader business focus and direction } \\
\text { career wise in order to consolidate learning in the workplace. }\end{array}$ \\
\hline Corporate social responsibility & $\begin{array}{l}\text { Business voluntarily contributes towards building a better } \\
\text { society and moves away from a bottom line mentality to } \\
\text { thinking of environmental and social issues. }\end{array}$ & $\begin{array}{l}\text { Offers the opportunity to build bridges between the organisation } \\
\text { and the community. Managers can practice skills in a safer } \\
\text { environment. }\end{array}$ \\
\hline Changing psychological contract & $\begin{array}{l}\text { Absence of employment for life and fewer opportunities } \\
\text { available for career progression. }\end{array}$ & $\begin{array}{l}\text { Support the concept of greater importance of self-development, } \\
\text { multi-tasking and self-reliance. }\end{array}$ \\
\hline Managing stress at work & Affecting the productivity and wellbeing of people. & $\begin{array}{l}\text { Give the opportunity to step back and assess the ways in which } \\
\text { work are approached. Assist people to deal with change and } \\
\text { manage transitions in their careers. }\end{array}$ \\
\hline $\begin{array}{l}\text { Work-life balance and flexible } \\
\text { arrangements }\end{array}$ & $\begin{array}{l}\text { Encouraging a healthy work-life balance and working } \\
\text { arrangements that suit both the individual and the organisation. }\end{array}$ & $\begin{array}{l}\text { Support people to feel in control of their lives. Help people feel } \\
\text { committed to the organisation and part of the team. }\end{array}$ \\
\hline
\end{tabular}


TABLE 2

\section{CONTEXT AND RATIONALE FOR METORING: INTERNAL INFLUENCES (CRANWELl-WARD ET AL, 2004)}

\begin{tabular}{|c|c|c|}
\hline Internal influences & Description & Importance of mentoring \\
\hline Core building capabilities & $\begin{array}{l}\text { Building the right skills and capabilities of employees to deliver } \\
\text { the organisation's strategy. }\end{array}$ & $\begin{array}{l}\text { Cost-effective way for individuals to develop their skills and } \\
\text { abilities to achieve goals. }\end{array}$ \\
\hline Succession planning & $\begin{array}{l}\text { Preparation of internal high potential employees to be recruited } \\
\text { from within the organisations for potential future vacant } \\
\text { positions. }\end{array}$ & $\begin{array}{l}\text { Knowledge and skills of senior managers are captured (and } \\
\text { transferred) thorough mentoring programmes before they leave } \\
\text { the company. }\end{array}$ \\
\hline War for talent & Attraction and retention of the best staff. & $\begin{array}{l}\text { Show future recruits and current employees that their } \\
\text { contribution to the organisation is recognised and valued. }\end{array}$ \\
\hline Business performance focus & $\begin{array}{l}\text { Focus on enabling organisational objectives through having the } \\
\text { right people on board to improve business performance. }\end{array}$ & $\begin{array}{l}\text { Mentoring for new staff helps them to contribute much faster, } \\
\text { because they understand how to get things done in the system. }\end{array}$ \\
\hline Increased motivation & $\begin{array}{l}\text { Investment in individuals can increase motivation, because } \\
\text { they feel valued and recognised by the organisation. }\end{array}$ & $\begin{array}{l}\text { The mentoring relationship itself can be motivational, providing } \\
\text { support and guidance to the mentee. }\end{array}$ \\
\hline $\begin{array}{l}\text { Facilitating teamwork and } \\
\text { productivity }\end{array}$ & $\begin{array}{l}\text { Greater need for working in a range of different teams and } \\
\text { situations requiring specific leadership skills. }\end{array}$ & $\begin{array}{l}\text { Mentors can help develop essential leadership and management } \\
\text { skills. }\end{array}$ \\
\hline Change management practices & $\begin{array}{l}\text { Change in terms of culture, strategy, organisational structures, } \\
\text { processes and procedures. }\end{array}$ & $\begin{array}{l}\text { Provide support and help people to move forward to manage the } \\
\text { change in the best way possible. }\end{array}$ \\
\hline Knowledge management & $\begin{array}{l}\text { The acquisition, development and sharing of knowledge are } \\
\text { key components of competitive advantage. }\end{array}$ & $\begin{array}{l}\text { Mentoring can assist with the sharing of knowledge, and ensures } \\
\text { that less knowledge is lost when senior managers resign or retire } \\
\text { form the organisation. }\end{array}$ \\
\hline $\begin{array}{l}\text { Individual development and } \\
\text { continuous improvement }\end{array}$ & $\begin{array}{l}\text { Greater emphasis on individual personal and professional } \\
\text { growth and development. }\end{array}$ & $\begin{array}{l}\text { The mentoring philosophy encourages mentees to take } \\
\text { responsibility for their own learning. }\end{array}$ \\
\hline
\end{tabular}

TABLE 3

BENEFITS OF MENTORING PROGRAMMES (Bush \& Coleman, 1995; Cranwell-Ward et al, 2004; Klasen \& Clutterbuck, 2002; Poe, 2002; Tyler, 1998)

\section{Mentee}

- Improved self-confidence and self-esteem

- Confidential coaching

- Safe learning environment to test ideas

- Continued support in a changing environment

- Access to different perspectives and experience

- Development of transferable skills, including management, leadership, behavioural, professional

- Sense of value in the organisation

- Opportunity to broaden networks

- Help in developing a long-term career, and development goals and plans

\section{Mentor}

- Improved job satisfaction/revitalised interest in work - be challenged, tested and stimulated

- An opportunity to influence the way things are done - passing on own experience, knowledge and skills

- Increased peer recognition - seen as a role model

- New perspectives - challenging own assumptions

- An opportunity to question their own views and values

- Opportunity to influence the next generation of managers and demonstrate their own commitment to the future of the company

- Self-development - using and improving skills

- Get/keep in touch with the grass roots level and manage their own team better as a result

\section{Organisation}

- Increased motivation/retention of employees by investing in their development

- Helps stabilise and reinforce the organisation's values and culture

- Professional standards are maintained

- Improved communications - both laterally and vertically, and particularly across cultures

- Productivity gains - mentees working smarter and developing two for the price of one

- Knowledge capital protection in sharing and retaining valuable knowledge encapsulated in experienced managers

- Enhances the practice and culture (if continuous learning)

- Improved succession planning because more information is available

- Increased speed of change

- Strengthening of business relationship
Implementing and sustaining a mentoring programme

Implementing and managing a mentoring programme involve behind the scenes tasks upon which not only the success of the initiative depends, but also the reputation of mentoring within the organisation for the foreseeable future (Blake-Beard, 2001; Conway, 1998; Cranwell-Ward et al, 2004; Klasen \& Clutterbuck, 2002; Tyler, 1998; Whittaker \& Cartwright, 2000). The objectives of the mentoring programme will, in general, determine the particular approach that should be followed in implementing the mentoring programme (Klasen \& Clutterbuck, 2002).

The six best practices discussed below come from the literature and are based on the researchers' practical experiences and lessons learned by the organisations they were involved in. Best practices have been developed in order to help navigate the design and implementation of mentoring programmes (Appelbaum et al, 1994; Conway, 1998; Cranwell-Ward et al, 2004; Forret, 1996; Fowler, 1998; Gibb, 1995;1999; Klasen \& Clutterbuck, 2002; Tyler, 1998).

Best practice 1: Preparing the implementation proposal and conducting the necessary research

According to Klasen and Clutterbuck (2002), the purpose of this practice is to evaluate the fit between the organisation and the intended mentoring programme, and to gather evidence that corroborates the argument in favour of the implementation of a proposed mentoring programme. The information acquired during the research phase allows the mentoring champion to assess and express the business consequences of progressing or not progressing with a mentoring programme. Preparatory research also provides a framework for the design and implementation of the programme. For example, by researching the needs of employees in the organisation, it is easier to set effective programme objectives and to identify the mentee target group. Furthermore, it enables mentoring champions to evaluate the risks to their reputation that are associated with pressing ahead with the mentoring programme. For instance, an organisational readiness analysis that reveals that the organisational culture is not conducive to a mentoring programme will prompt mentoring champions to stop and rethink their efforts. This may save them great potential embarrassment (Conway, 1998; Forret, 1996; Klasen \& Clutterbuck, 2002). According to Klasen and Clutterbuck (2002), an organisational readiness analysis should provide answers to the questions in table 4. 
TABLE 4 QUESTIONS TO ESTABLISH ORGANISATIONAI
READINESS FOR MENTORING

(Klasen \& Clutterbuck, 2002:195)

\section{Value attached to human resources development (HRD)} in general?

\section{Does management view HRD as} a priority?

Do managers allow time for employees to engage in training and development activities, or are other tasks always more important?

Are financial resources readily available for employee

development?

Is the management philosophy to grow talent as opposed to buying it?

Do employees value development opportunities?

Are the people who develop others recognised for this?

Is the organisation generally committed to and supportive of the evaluation of development activities?

Viability of a mentoring programm (as opposed to other training and development approaches)?

Would a mentoring programme fit in with the organisational culture?

Would top and middle management embrace it wholeheartedly, that is would they act as mentors themselves and would they support it?

Are employees likely to be receptive to mentoring? Will they be interested in taking it up or would it not appeal to them?

Does your culture encourage personal change and development, and value initiative and risk taking?

Would you be able to recruit sufficient numbers of volunteer mentors?

Will sufficient numbers of off-line mentors be available?

Are your potential mentors able and willing to persist with the relationship for its entire duration?

Will you be able to find the right people for the design, implementation and running of the programme?

Will it be possible to integrate mentoring with the total programme of employee training and development?
Best practice 2: Identifying key stakeholders and gaining organisational commitment

Cranwell-Ward et al (2004) state that the informed support of the key stakeholders for a mentoring programme is vital to the viability of the programme, because successful mentoring depends on the context and climate in which mentoring occurs. The key stakeholders therefore play a significant part in creating the right setting. Organisational commitment depends widely on the core value proposition of the mentoring programme and on how it is positioned in the organisation. Clear statements of intent, programme scope, objectives and expectations, practical application and evaluation systems support the justification of such programmes (Conway, 1998; Fowler, 1998; Klasen \& Clutterbuck, 2002; Tyler, 1998).

\section{Best practice 3: Marketing the mentoring programme}

Determining the most appropriate way to market and promote a mentoring programme is important because it supports the organisation in gaining interest for mentoring programmes and finding volunteers to participate (Appelbaum et al, 1994; Clutterbuck, 2001). In organisations that foster a learning culture, mentoring would be a natural fit. However, methods such as distribution of booklets, compiling policy and process documents, mentoring websites on the intranet, internal champions, information workshops and communiqués via email can support potential and interested participants in the programme by helping them to gain a fuller picture of what might be involved (Cranwell-Ward et al, 2004; Klasen \& Clutterbuck, 2002)

\section{Best practice 4: Mentoring programme design and} development

The development and design of a mentoring programme starts by defining the key principles that will underpin the mentoring relationship (Cranwell-Ward et al, 2004). Such principles include the values of the organisation, define the target group of the programme, indicate from where mentors will be drawn and provide detailed guidance on how the programme will operate (Conway, 1998; Forret, 1996; Gibb, 1995;1999; Klasen \& Clutterbuck, 2002; Tyler, 1998).

Once the overall approach has been defined and outlined, it is important to consider the practical components that will support the process. These may include defining the roles and responsibilities of key stakeholders; resourcing levels necessary to support the proposed size of the programme; determining how technology will be used to promote and administer the programme; defining qualities to look for in mentors and mentees; establishing guidelines on meeting frequency, length and location; suggestions for the first meeting and ongoing discussion topics; determining how matching will be done, what will happen if the relationship does not work and what training will be required (Cranwell-Ward et al, 2004). As part of the design and planning phase, Tyler (1998) suggests that it is useful to generate pro-formas to assist with the information gathering process.

Best practice 5: Maintenance, concluding and further development of the mentoring programme

Once a mentoring programme is implemented, it is important to address the various hurdles associated with the successful implementation of the programme (Forret, 1996; Klasen \& Clutterbuck, 2002). An audit by Clutterbuck \& Sweeney (2003) revealed that mentoring programmes that do not deliver results generally share the following failures:

- Poor planning and preparation.

- Inadequate education of third parties, such as the learners' coworkers who are not included in a mentoring programme.

- Inability of some managers to adopt mentoring behaviours in other than a mechanistic manner.

- Inadequate training of participants.

- Low clarity on roles and responsibilities of mentor and mentee - who does what?

- Too little or too much formality.

- Inadequate championship from the top. The most successful mentoring programmes are often those where top managers are open about their own beneficial experiences of mentoring and willing to discuss them with others in the organisation.

Maintenance in the form of support to mentors and mentees, regular contact with participants, setting up formal and informal reviews, sharing success stories, mentoring mentors, additional training of mentors and dealing with difficult personal situations help to keep the programme on track (Appelbaum et al, 1994). A mentoring programme has much to offer in terms of increasing organisational effectiveness and competitiveness. However, it requires a planned approach to implementation and ongoing support (Clutterbuck \& Sweeney, 2003).

An effective mentoring relationship follows a lifecycle. As the relationship draws to a close, it is vital to conclude it in a proper manner. Cranwell-Ward et al (2004) uphold that activities such as evaluation of the relationship, termination of the formal mentoring partnership, indication of options available for further development, recognition of achievements, key messages to be taken forward and sharing experiences in a formal way support the conclusion of the mentoring lifecycle in an effective way.

A basic mentoring programme that achieved the anticipated objectives can lead to organisations becoming interested in expanding the process further (Cranwell-Ward et al, 2004; Klasen \& Clutterbuck, 2002; Tyler, 1998). The programme is therefore able to grow organically, as ex-mentees become the next generation of mentors and champions, and the number of individuals who can help with any or all parts of the process grows (Cranwell-Ward et al, 2004). 
To capitalise on the success of a current programme, organisations can consider extending the programme within the targeted group, targeting another group or opening it up to all employees (Gibb, 1995). However, extending and developing a programme can put pressure on resources (people, budget, mentor pool, training requirements). The use of technology (use of website, telephone systems to facilitate meetings, e-mail to facilitate communication), alternative administration procedures (software for matching, data capturing, database management) and peer mentoring (sharing experiences and best practices) facilitate growing a mentoring programme (Cranwell-Ward et al, 2004; Klasen \& Clutterbuck, 2002).

\section{Best practice 6: Evaluation and review of the} mentoring programme

Although mentoring is ultimately a private relationship between the mentor and the mentee, it is not only necessary to have a formal evaluation and review structure in place at the end of the mentoring programme, but also to have an ongoing review process as part of the programme maintenance activities. This enhances the overall evaluation of the programme (Appelbaum et al, 1994; Cranwell-Ward et al, 2004; Klasen \& Clutterbuck, 2002).

In general, Cranwell-Ward et al (2004) suggest that an evaluation strategy should use multiple methods and obtain both quantitative (objective, numerical or hard) data and qualitative (subjective, non-numerical and soft) data that should be in place at the beginning of the programme. Therefore stakeholders should be involved in setting success criteria and should build these into the evaluation process from the beginning. In addition, it is vital to obtain baseline data against which any changes can be measured (Gibb, 1995; 1999). Possible measures will depend on the purpose of mentoring, but may include aspects such as recruitment levels and vacancies, promotion rates, readiness for higher level responsibilities, employee skills and competencies, attitudes and motivation of both mentees and mentors, cost of training and development, and public opinion about the organisation. Megginson and Clutterbuck (1995) report that basic elements for measuring a mentoring programme include evaluation on a programme level (processes and outputs) and a relationship level (processes and outputs). The evaluation of a mentoring programme includes people like the mentor and mentee themselves, line managers and other stakeholders, mentoring programme administrators, the programme manager and an objective third party such as the Human Resources Department (Gibb, 1995;1999; Klasen \& Clutterbuck, 2002; Murray \& Owen, 1991; Segal, 2000).

Research on mentoring practices in the South African organisational context is limited. The aim of this study was therefore to investigate the practices employed by South African companies to implement and sustain their mentoring programmes.

\section{RESEARCH DESIGN}

\section{Research approach}

According to Kerlinger and Lee (2000), the main criterion of a research design is that it should adequately answer the research question. A qualitative approach was decided upon, since as this approach is specifically suitable when the research takes place in a natural setting. Qualitative research attempts to make sense of and interpret constructs and phenomena in terms of the meanings that people ascribe to them, thus seeking to give meaning to social experience (Denzin \& Lincoln, 1994). Silverman (2000) asserts that qualitative studies are commonly believed to provide a deeper understanding of the phenomenon being investigated. Since the research questions pertain to understanding and describing a particular phenomenon about which very little is known, the qualitative approach appeared to be the most suitable for gaining insight about respondents' views on the mentoring practices that contribute to the overall success of the mentoring programme in the company (Creswell, 1994).

This study was therefore conducted within a qualitative paradigm and the grounded theory method was used to develop an inductively derived theory (Strauss \& Corbin, 1990). This method enabled the researcher to study the phenomenon (the mentoring programme) within its context and facilitated the systematic generation of theoretical principles from, and grounded in, the data regarding the respondents' viewpoints on the particular mentoring practices within the company.

\section{Respondents}

A purposive sample (Huysamen, 1994), comprising three designated representatives from three organisations in Gauteng who are responsible for overseeing the implementation and management of the mentoring programme in their respective companies, was used for the present study. Background information on the three selected organisations is provided in table 5. From table 5 it appears that the participating organisations cover a wide range of different economic activities and represent a wide spread in the number of employees employed by each organisation.

\section{TABLE 5}

\section{Background information: Participating organisations}

\begin{tabular}{llc}
\hline Organisation & Industry and type of business & Employees \\
\hline A & $\begin{array}{l}\text { Financial services: Large banking group with } \\
\text { approximately 650 branches nationally }\end{array}$ & 34,000 \\
B & $\begin{array}{l}\text { Professional services: Small recruitment and } \\
\text { selection operation }\end{array}$ & 50 \\
C & $\begin{array}{l}\text { Health care: Large provider of health care } \\
\text { related services with branches in all the } \\
\text { major sectors }\end{array}$ & 600 \\
\hline
\end{tabular}

\section{Method of data gathering}

The study was conducted within a qualitative research paradigm. The qualitative data collection technique in this study included a semi-structured qualitative interview with each respondent. The interview schedule was developed after review of the literature. Each interview lasted approximately 60 to 90 minutes and was structured around the two research questions. All interviews were ended with an open question allowing for the respondents to share any information or experience they felt were relevant, and that had not been explored or discussed during the interview.

The following two open-ended questions were carefully formulated and put to the respondents:

- What is the structure of the company's mentoring programme?

- Which practices contribute to the overall success of implementing and sustaining the mentoring programme?

\section{Procedure}

The three organisations were approached telephonically and invited to participate in the research. The nature of the study was described, an assurance of anonymity was given and a report back on the findings was offered. It was agreed that the details of the report back meeting would be discussed at a future date. Arrangements were made to personally interview each designated representative at a convenient time and location. The researcher interviewed each designated representative individually. 
Data analysis

All the data gathered through the interviews were analysed by means of a qualitative, interpretative analysis and (more specifically) a content analysis (Berg, 2001). Inferences and interpretations were made on inspection of the data gathered. In conclusion, the common themes were interpreted in the light of existing literature on the topic, enabling meaningful interpretation of the results. Table 6 was designed to illustrate and structure the analyses of the data received in response to the two research questions.

TABLE 6

KEY BEST PRACTICES FOR IMPLEMENTING AND SUSTAINING MENTORING PROGRAMMES

\begin{tabular}{|c|c|}
\hline Organisation & Best practices: Success drivers \\
\hline A & $\begin{array}{l}\text { - Support, commitment and sponsorship of the } \\
\text { programme by senior management } \\
\text { - A clear value proposition for the programme } \\
\text { - Programme co-ordination from a head office sponsor } \\
\text { working in combination with regional HR consultants } \\
\text { that manage operations } \\
\text { - Use of technology to support knowledge sharing } \\
\text { - The mentors are experienced managers } \\
\text { - The design of the programme should fit in with the } \\
\text { culture of the organisation } \\
\text { - Training mentors to ensure their expectations are } \\
\text { reasonable; how to communicate effectively and } \\
\text { strategies to deal with difficult situations } \\
\text { - Use formal and informal metric systems to evaluate and } \\
\text { benchmark the programme }\end{array}$ \\
\hline B & $\begin{array}{l}\text { - Driven by top management } \\
\text { Mentoring used as a vehicle to create a learning } \\
\text { organisation to enable development planning } \\
\text { - Every employee (irrespective of level) should have access } \\
\text { to a mentor } \\
\text { - There should be an action plan for implementation, } \\
\text { which include time, resources, budget and facilities } \\
\text { considerations } \\
\text { - A mentorship culture should be developed in the } \\
\text { organisation } \\
\text { Mentorship should be incorporated into performance } \\
\text { management }\end{array}$ \\
\hline $\mathrm{C}$ & $\begin{array}{l}\text { - Strong commitment from senior management to } \\
\text { encourage participation } \\
\text { - Have a robust, scalable infrastructure to support the } \\
\text { implementation } \\
\text { - Selection of departmental champions to help implement } \\
\text { and administer the programme } \\
\text { - Strong commitment from mentees to self-direct the } \\
\text { mentoring relationship } \\
\text { - Participation on a voluntary basis is better than forced } \\
\text { involvement }\end{array}$ \\
\hline
\end{tabular}

\section{RESULTS}

The main findings indicated that the purposes for which the mentoring programmes were established included the training and development of junior and high potential leaders; socialisation of new employees, career development and providing assistance and support. The mentoring structures ranged from being formal to less formal. In addition, the implementation approach appeared to be influenced by the overall goal of the mentoring programme. Generally, the results suggested that the success of the mentoring programmes could be attributed to the six best practices determined in the literature review. More specifically, the following common elements appeared to be important in all three companies: clear programme objectives; identification of key stakeholders and obtaining commitment from senior managers, mentors and mentees; identification of the target group and guidance on how the mentoring programme will operate; organisational support and coordination to sustain the programme; and formal attempts to evaluate the effectiveness of the programme.
As suggested by Strauss and Corbin (1990), several themes relating to the phenomenon of mentoring practices emerged from the data analysis. In the next section these themes will be discussed. From the themes it was possible to develop responses to the formulated research questions and to link international studies with the results of this study.

\section{Key best practices: Organisation A}

Organisation A has a formal mentoring programme. The organisation plays a central role in establishing mentoring relationships and monitoring the progress and results of the programme. The mentoring programme is targeted at groups of employees and focuses mostly on junior managers and supervisors, with the goal of developing high potential leaders who can fill executive positions in the event of retirement or resignation. Mentors and mentees are nominated and selected to participate in the programme, and a total of 50 mentees and mentors are chosen per cycle. A group of specialised human resources employees conduct assessments and interviews with selected participants in order to pair mentors and mentees with each other. A head office programme manager and two programme administrators oversee the overall programme administration, support and evaluation.

Regional branch human resources consultants ensure the day-today administration of the programme in different regions. The organisation conducts two-day introduction orientation programmes for mentoring pairs. Executive management displays their commitment to the programme by conducting the opening session of the orientation workshop. The formal duration of the programme is 18 months, and it is advised that meetings take place every four to six weeks. The organisation places much of the responsibility for the pairs' scheduling meeting on the shoulders of the mentees. The organisation solicits feedback from participants through a formal quarterly review process, during which the head office programme management team conduct individual in-dept interviews with each mentee and mentor. The feedback is used to determine positive and negative aspects of the programme, and is integrated with future programme planning.

\section{Key best practices: Organisation B}

The mentoring philosophy at organisation B revolves around the holistic development of individuals who are competent in their role but seek growth and development in all aspects of their lives (including work, professional and personal areas). The organisation recently embarked on this mentoring structure and the initial priority is to provide mentors for all experienced and competent labour recruitment learners, new managers and individuals in new positions. Once this has been rolled out, mentoring will be offered to the rest of the organisation. The idea behind mentoring is that employees at any level will be mentored by employees at a higher level than themselves. Top management in the organisation act as sponsors of the mentoring programme and display their commitment visibly by personally being a mentor.

The mentoring programme is voluntary and individuals who are working at the organisation for more than one year can apply to participate in the programme. The organisation identifies three possible mentors and a programme co-ordinator liaises with the identified mentors to assess their willingness to participate as in the programme. After mentoring pairs have been established, workshops are conducted with mentors and mentees. These workshops focus on elaborating on mentor's responsibilities and their influence on the mentoring process. Skills development plans are discussed and the attributes that are required of a mentor are identified and discussed. The programme is informal and mentoring pairs meet on a monthly basis for a period of one year. The organisation conducts "smile sheet" evaluations at the end of the mentoring programme to collect information on the success of the programme. 
Key best practices: Organisation $\mathrm{C}$

Mentoring at organisation $\mathrm{C}$ is structured in a less formal manner, although the organisation supports the programme and exerts some influence upon or authority over the progression of the mentoring relationships.

The programme aims to provide participants with the opportunity to be part of a mentoring relationship for the purposes of career development. The organisation employs a self-directed and mentee-driven approach in which a mentee takes personal responsibility for identifying and recruiting a mentor to act as informal coach and counselor to assist with career development. Employees at all levels can participate in the self-directed mentoring programme and programme guidelines, questions and answers, tips, online mentoring induction, toolkits and a list of available mentoring resources are provided on the organisation's intranet. The guidelines include a definition of the programme, the essential factors for a successful mentoring relationship, roles of the mentor and the mentee, and action steps for the mentee to manage the programme.

Programme administrators are mostly responsible for keeping the content of the website current and participants are able to tailor the programme to their specific needs. The organisation does not prescribe a specific time period for the mentoring relationship; however, it sees one year as a reasonable time period for a relationship to mature and conclude. The company requires mentors and mentees to formally evaluate the mentoring programme three times a year. Evaluations are conducted online and feedback are integrated into the programme content on a continual basis in order to update and increase the success of the programme.

\section{DISCUSSION}

As stated, the main purpose of this study was to explore the application of best practices by South African companies in implementing and sustaining mentoring programmes. The data gathered from the respondents' subjective perspectives of their companies' mentoring practices will be discussed by relating the views of the respondents to existing empirical findings and relevant abstract theoretical concepts.

Given the impact of development initiatives in the South African organisational context, mentoring programmes appear to become a popular talent development tool in organisations. However, mentoring programme design and implementation are challenging and complex, and many programmes fail due to a lack of adequate resources and time (Blake-Beard, 2001; Klasen \& Clutterbuck, 2002; Poe, 2002).

From the investigation of the mentoring programmes practised at the three organisations that participated in the study, it appears that the success of mentoring programmes could be attributed to a strong commitment from senior or executive management (Clutterbuck, 2001; Klasen \& Clutterbuck, 2002). Having the programme formalised created responsibility for and commitment to the mentoring process. In addition, the results suggested that the implementation of mentoring programmes could be sustained through organisational support mechanisms such as the administration and overseeing of the operational process by a programme co-ordinator. It seems that the implementation of mentoring programmes is aided by the use of technology that helps to increase the sharing of knowledge among mentoring participants and which provides administrators with the tools to manage the day-to-day operations more efficiently. The investigation seems to indicate that the design and implementation of a valuable mentoring programme require adequate resources, time, facilities and true commitment from business leaders (Klasen \& Clutterbuck, 2002; Scandura \& Williams, 2002).
Apart from leadership commitment and resource requirements, it is evident from the investigation that the identification of the purpose, objectives, scope and approach of mentoring programmes require equal deliberation. The purpose of a mentoring programme describes the reason for introducing the programme in the organisation and helps to clarify the rationale behind the programme (Conway, 1998; Forret, 1996; Klasen \& Clutterbuck, 2002; Cranwell-Ward et al, 2004). For potential mentors and mentees, programme objectives provide a focus on what should be achieved during the time available for the relationship. The scope of the programme refers to the size and extent of the mentoring programme, while the approach covers elements of formalisation (formal to informal) of the programme (BlakeBeard, 2001; Cranwell-Ward et al, 2004; Klasen \& Clutterbuck, 2002).

In this investigation the purpose and scope of the programmes varied from being used for the development of selected high performing individuals as part of a succession planning strategy to providing general development and growth opportunities to employees on all levels in the organisations. The approach of the programmes implemented by these organisations includes elements of formal, informal and self-directed principles. The results seem to indicate that the purpose and approach to structuring mentoring programmes depends on the specific needs and strategy of the organisation, and on the context in which the programme is introduced. It is therefore well aligned with best practice.

When selecting and pairing mentees and mentors, the approach varies from assigning mentors to mentees through a formal nomination and selection process to volunteer participation from both the mentor and mentee (Scandura \& Williams, 2002). Regardless of the method of matching mentees and mentors, it is important to have a formal structure with supporting documentation in place that gives guidelines on what criteria should be used, what will happen if the relationship does not work and how transparent the process should be (Clutterbuck, 2001; Cranwell-Ward et al, 2004; Klasen \& Clutterbuck, 2002). Ultimately, both mentor and mentee should assess whether they will be able to relate to one another to make the experience a worthwhile one. Furthermore, to attain success in the mentoring programme it appears important that mentors and mentees join the programme voluntarily and that making mentors accountable and mentees responsible for their own learning can increase their level of commitment to the relationship ( Scandura \& Williams, 2002).

It is evident from the investigation that before embarking on a mentoring relationship, organisations should engage in training or orientation of mentors and mentees. Training and orientation sessions help to explain the mentors' primary role and inform them of the time and energy required for the relationship (Klasen \& Clutterbuck, 2002). The training of mentees seems to be equally important as a means to clarify their roles and responsibilities, provide career assessments to outline goals and assist with guidance on what is expected from them. It seems that the orientation workshops provide a framework for the mentoring relationship and touch on elements such as the regularity of meetings, agenda and discussion points, practical process, action steps, evaluation and review of the success of the relationship. From a best practice perspective, it seems that less importance is placed on concluding the relationship in an effective manner.

In this regard, organisations may consider arranging meetings, parties or events to conclude formal mentoring programmes in an appropriate manner (Forret, 1996; Cranwell-Ward et al, 2004; Klasen \& Clutterbuck, 2002). This will give organisations the opportunity to celebrate successes and achievements, and will 
enable participants to discuss and share their most memorable experiences and the lessons learned.

The organisations profiled in the investigation rely on a variety of systems and practices to evaluate the effectiveness of their mentoring programmes, such as formal evaluation forms, structured interviews with mentors and mentees, and informal feedback from participants (Scandura \& Williams, 2002). It seems that these organisations rely mostly on subjective and non-numerical data to support their evaluation processes. According to best practice, organisations may consider incorporating additional numerical performance measures to link the mentoring programme objectives to tangible, expected results (Klasen \& Clutterbuck, 2002; Tyler, 1998). A mentoring programme dashboard with objective and subjective metrics can provide an overview and visual display of the overall effectiveness and success of the programme. It may also be useful to benchmark the components of the mentoring programmes with other organisations in the market to gain an understanding of areas that require improvement (Conway, 1998; Cranwell-Ward et al, 2004).

Today's world is changing, turbulent and competitive. It requires people and organisations to change and grow if they want to stay ahead of the game. If development is a key driver for organisational business performance, then mentoring should move towards the centre of the development strategy. Implementing and sustaining a mentoring programme require careful consideration and planning. As this study has indicated, mentoring can provide enormous benefits to both the individual and the organisation. It is also recommended that organisations offer formal mentoring in partnership with informal mentoring so that mentees can receive the greatest benefits (Ragins \& Cotton, 1999). Since formal programmes are less successful than informal mentorship, organisations should encourage employees to form networks with ties to higherlevel managers, peers, employees, and outsiders (Scandura \& Williams, 2002).

One of the goals of many formal mentoring programmes is to bring the organisation to the point where the majority of mentoring is carried out informally, without the need for substantial, structured support from human resources and others (Clutterbuck \& Sweeney, 2003). The problem in most cases is that completely informal mentoring (where people come together without guidance and without clarity about the mentoring role) is a hit and miss affair. Not only is the quality of relationships highly variable, but the pairings tend to exclude people who do not fit the mould by virtue of their gender, race, culture or some other differentiating factor. In general, organisations that have a strong and extensive formal mentoring process seem also to develop many thriving, healthy and inclusive informal mentoring relationships. The key factor appear to be that people, who have experienced effective mentoring (as mentors or mentees) and who have been trained well in their respective roles, are open to a wider range of developmental alliances. In particular, they appreciate the value of difference and stretch in a learning relationship, and seek out challenging partnerships. However, this is an area for future research because currently no significant research is available and the evidence is largely anecdotal (Hay, 1995; Clutterbuck \& Ragins, 2002; Klasen \& Clutterbuck, 2002).

The qualitative nature of this study had the limitation that it was not always possible to obtain all the detailed information normally required in this type of study. The reason for this is because organisations often regard areas of their programmes as confidential in order to maintain a competitive advantage over adversaries. With regard to follow-up research, an expansion of the sample is highly recommended. This would also lead to a more in-depth study of mentoring in the broader South African context.

\section{REFERENCES}

Allen, T.D. \& Poteet, M.L. (1999). Developing effective mentoring relationships: strategies from the mentor's viewpoint. Career Development Quarterly, 48, 59-73.

Appelbaum, S.H., Ritchie, S. \& Shapiro, B. T. (1994). Mentoring revisited: an organisational behaviour construct. The International Journal of Career Management, 6 (3), 3-10.

Baruch, Y. (1999). Integrated career systems for the 2000s. International Journal of Manpower, 20 (7), 432-457.

Baruch, Y. (2002). Career systems in transition: a normative model for organisational career practices. Personnel Review, 32 (2), 231-251.

Baruch, Y. (2004). Transforming careers: from linear to multidirectional career paths: organisational and individual perspectives. Career Development International, 9 (1), 58-73.

Berg, B.L. (2001). Qualitative research methods for the social sciences. Boston: Allyn \& Bacon.

Blake-Beard, S.D. (2001). Taking a hard look at formal mentoring programs. Journal of Management Development, 20 (4), 331-345.

Brown, T. L. (1990). Match up with a mentor. Industry Week, 239, 1.

Burke, R.J., McKeen, C. A., \& McKenna, C. (1994). Benefits of mentoring in organisations. The mentor's perspective. Journal of Managerial Psychology, 9 (3), 23-32.

Bush, T. \& Coleman, M. (1995). Professional development for heads: the role of mentoring. Journal of Educational Administration, 33 (4), 60-73.

Clutterbuck, D. (2001). Everyone Needs a Mentor: Fostering Talent at Work. London: CIPD.

Clutterbuck, D. \& Lane, G. (2005). The Situational Mentor. London: Gower.

Clutterbuck, D. \& Ragins, B.R. (2002). Mentoring and Diversity: An International Perspective. Johannesburg: ButterworthHeinemann.

Clutterbuck, D. \& Sweeney, J. (2003). Coaching and Mentoring. Burnham: Clutterbuck \& Associates.

Conway, C. (1998). Strategies for Mentoring: A Blueprint for Successful Organisational Development. Chichester:Wiley.

Corporate Leadership Council. (1999). Mentoring - A Theoretical Perspective. (Report No. 070-238-104). London: Corporate Leadership Council, Corporate Executive Board.

Cranwell-Ward, J., Bassons, P. \& Gover, S. (2004). Mentoring. A Henley Review of Best Practice. New York: Palgrave MacMillan.

Creswell, J.W. (1994). Research design: qualitative and quantitative approaches. California: Sage Publications.

Denzin, N.K. \& Lincoln, Y.S. (1994). Handbook of qualitative research. Thousand Oaks, CA: Sage.

Finkelstein, L.M., Allen, T.D., \& Rhoton, L.A. (2003). An examination of the role of age in mentoring relationships. Group \& Organisation Management, 28 (2), 249-281.

Forret, M.L. (1996). Issues facing organisations when implementing formal mentoring programmes. Learning and Organisational Development Journal, 17 (3), 27-30.

Fowler, A. (1998). How to: mentoring guidelines. People Management, October, 48-50. Gibb, S. (1995). Evaluating mentoring. Education + Training, 36 (5), 32-39.

Gibb, S. (1999). The usefulness of theory: a case study in evaluating formal mentoring schemes. Human Relations, 52 (8), 1055.

Gunn, E. (1995). Mentoring: the democratic version. Training, 64-67.

Hay, J. (1995). Transformational Mentoring. New York: McGraw-Hill.

Hall, D.T. \& Kahn, W.A. (2002). Developmental relationships at work: A learning perspective. In C.L. Cooper \& R.J. Burke (Eds.). The new world of work: Challenges and opportunities, 49-74. Oxford: Blackwell.

Henley Management College, (2000). E-business Management in the New Economy. Henley Management College.

Huysamen, G.K. (1994). Methodology for the social and behavioural sciences. Halfwayhouse: Southern.

Kerlinger, F.N. \& Lee, H.B. (2000). Foundations of behavioural research. New York: Harcourt College. 
Klasen, N. \& Clutterbuck, D. (2002). Implementing Mentoring Schemes: A Practical Guide to Successful Programs. London: Butterworth-Heinemann.

Kram, K. E. (1985). Mentoring at Work. Development Relationships in Organisational Life. London: Scott, Foresman and Company.

Megginson, D. \& Clutterbuck, D. (1995). Mentoring in Action. London: Kogan Page.

Murray, M. \& Owen, M.A. (1991). Beyond the Myths and Magic of Mentoring - How to Facilitate an Effective Mentoring Program. London: Jossey-Bass.

Parsloe, E. (1992). Coaching, Mentoring and Assessing: A Practical Guide to Developing Competence. London: Kogan Page.

Poe, A.C. (2002). Launching a Mentoring Program. Society for Human Resource Management White Paper. Available: www.shrm.org (2004, July 4).

Samier, E. (2000). Public administration mentorship: conceptual and pragmatic considerations. Journal of Educational Administration, 38 (1), 83-101.
Segal, J. (2000). Mirror-image mentoring. HR Magazine, 45, 157-162. Scandura, T.A. \& Williams, E.A. (2002). Formal mentoring: The promise and the precipice. In C.L. Cooper \& R.J. Burke (Eds.). The new world of work: Challenges and opportunities, 49-74. Oxford: Blackwell.

Silverman, D. (2000). Doing qualitative research: A practical handbook. London: Sage.

Sketch, E. (2001). Mentoring and coaching help employees grow. HR Focus, 34, 23.

Strauss, A. \& Corbin, J. (1990). Basics of qualitative research: grounded theory. Procedures and techniques. Newbury Park: Sage.

Triple Creek Associates. (2004). Mentoring Guide for Mentees. Available: http://www.3creek.com (2004, July 3).

Tyler, K. (1998). Mentoring programs link employees and experienced execs. HR Magazine, 31, 100-101.

Whittaker, M. \& Cartwright, A. (2000). The Mentoring Manual. London: Gower. 